\title{
Pulsatile glucagon has greater hyperglycaemic, lipolytic and ketogenic effects than continuous hormone delivery in man: effect of age
}

\author{
G.Paolisso ${ }^{1}$, S.Buonocore ${ }^{1}$, S. Gentile ${ }^{1}$, S. Sgambato ${ }^{2}$, M. Varricchio ${ }^{1}$, A. Scheen ${ }^{3}$, F. D'Onofrio ${ }^{2}$ and P.J.Lefèbvre $^{3}$ \\ ${ }^{1}$ Istituto di Gerontologia e Geriatria, ${ }^{2}$ Istituto di Medicina Generale, Terapia Medica e Malattie del Metabolismo, 1st Medical School, \\ University of Naples, Naples, Italy and ${ }^{3}$ Diabetes, Nutrition and Metabolic Disorders Unit, University of Liège, Liège, Belgium
}

\begin{abstract}
Summary. The present study aimed at investigating the hyperglycaemic, lipolytic and ketogenic effects of small doses of glucagon delivered continuously or in a pulsatile manner. The study was performed in eight healthy young volunteers $(24.2 \pm 1.2$ years $)$ and in eight healthy aged subjects $(69.4 \pm 2.0$ years). In all the subjects, endogenous pancreatic hormone secretion was inhibited by somatostatin and only glucagon was replaced. Consequently, the effects of pulsatile and continuous glucagon delivery were studied in conditions of progressive somatostatin-induced insulin deficiency. In both the young and the aged subjects, pulsatile glucagon delivery resulted in increases in plasma glucose, non-esterified fatty acid, glycerol and $\beta$-hydroxybutyrate levels greater than those observed when the same amount of glucagon was delivered in a continuous manner. The net increases in plasma glucose, glycerol and non-esterified fatty acid levels were similar between the young and the aged subjects when gluca-
\end{abstract}

gon was infused continuously; in contrast, the rise in plasma $\beta$-hydroxybutyrate in the aged was only about half that observed in the young subjects. Surprisingly, when glucagon was infused in a pulsatile manner, the rises in plasma glycerol, non-esterified fatty acid and $\beta$-hydroxybutyrate levels were all significantly smaller in the aged subjects, while no significant differences were observed in the blood glucose responses. We conclude that, in the presence of somatostatin-induced insulin deficiency, pulsatile glucagon exerts greater effects on blood glucose, plasma non-esterified fatty acid, glycerol and $\beta$-hydroxybutyrate levels than its continuous delivery. In the elderly, the lipolytic and ketogenic, but not the hyperglycaemic, responses to pulsatile glucagon are significantly reduced.

Key words: Glucagon, glycerol, $\beta$-hydroxybutyrate, ketogenesis, lipolysis, non esterified fatty acids, pulsatility.
Despite abundant information about pulsatile pancreatic hormone secretion [1-3], the metabolic impact of circulating hormone oscillations remains unclear. In particular, if little doubt exists that pulsatile insulin delivery is more efficient than continuous administration of an identical dose of this hormone for decreasing blood glucose $[4,5]$ and hepatic glucose production $[6,7]$, some controversy on the metabolic consequences of pulsatile glucagon delivery still exists. In fact, previous in vitro data [8-10] have shown that pulsatile glucagon has a greater enhancing effect on hepatic glucose output and optimises glucose production; in contrast, in a previous report, our group [11] failed to demonstrate such a superior effect of pulsatile glucagon in young healthy subjects. We hypothesized that the peripheral high circulating levels of glucagon achieved in that study, and the characteristics of glucagon kinetics in vivo in man, were probably responsible for the discrepancy between the in vitro [8-10] and the in vivo data [11].

Consequently, in the present study, also performed in healthy subjects, we investigated the effects of lower rates of pulsatile vs continuous glucagon delivery on plasma glucose, non-esterified fatty acid (NEFA), glycerol and $\beta$-hydroxybutyrate levels. Endogenous pancreatic hormone secretion was inhibited by somatostatin and glucagon was replaced at a dose which, in the continuous mode of infusion, was calculated to perfectly maintain basal plasma hormone circulating levels. Since animal studies had shown that glucagon-induced lipolysis and ketogenesis were reduced by aging [12], we decided to perform our studies in both young and aged healthy volunteers.

\section{Subjects and methods}

\section{Subjects}

Eight healthy young (age: $24.2 \pm 1.2$ years; $\mathrm{BMI}=21.0 \pm 0.5 \mathrm{~kg} / \mathrm{m}^{2}$ ) and eight healthy aged (age: $69.4 \pm 2.0$ years; $\mathrm{BMI}=21.5 \pm$ $0.4 \mathrm{~kg} / \mathrm{m}^{2}$ ) subjects volunteered for the study. None had a family history of diabetes or had taken any drug for at least three weeks before starting the experiments. All the subjects gave an informed consent and the study was approved by the Ethical Committee of our institution. All were consuming a regular, weight-maintaining diet.

\section{Experimental design}

The subjects were studied in the morning, starting at 08.00 09.00 hours after a $12 \mathrm{~h}$ overnight fast. All the subjects were placed on bed-rest and remained supine throughout the whole experiment. An 18-gauge polyethylene catheter was inserted into an antecubital vein of one arm and used for all infusions. A superficial dorsal hand vein was cannulated in anterograde fashion 

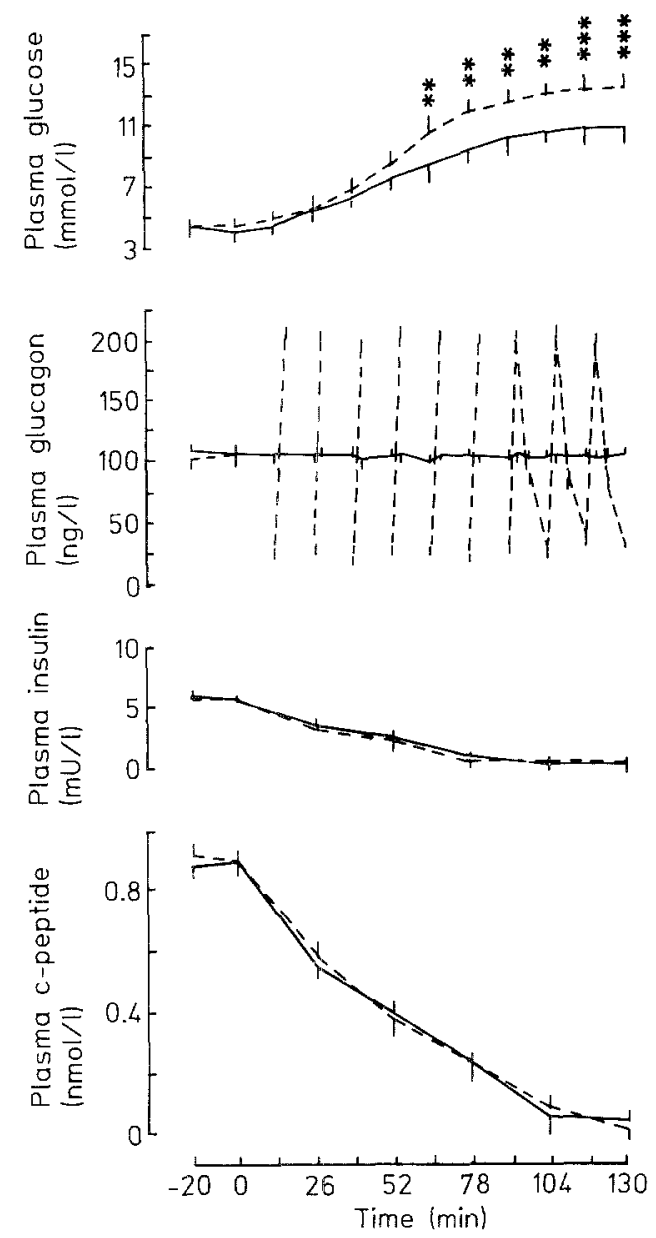

Fig. 1. Plasma glucose, glucagon, insulin and C-peptide levels during continuous ( - ) and pulsatile (-.---) glucagon infusion in young subjects. Multiple collections of blood permitting demonstration of oscillations in plasma glucagon were performed from 91 to $130 \mathrm{~min}$ only. Results are expressed as mean $\pm \operatorname{SEM}(n=8)$. Statistically significant differences are $* * * 0.005 ; * * * * 0.001$

with a 19-gauge butterfly needle and kept patent by a slow infusion of $0.9 \% \mathrm{NaCl}$; the hand was kept warm by an electric lamp for intermittent sampling of partially arterialized venous blood.

Each subject was tested on two occasions, in random order, separated by at least 1 week. In one experiment glucagon (Novo Industri, Copenhagen, Denmark: $58 \mathrm{ng} / \mathrm{min}$ ) was infused continuously; in the second experiment glucagon was infused in a pulsatile manner ( $377 \mathrm{ng} / \mathrm{min}$ during $2 \mathrm{~min}$ followed by $11 \mathrm{~min}$ during which no glucagon was infused). In all experiments, simultaneously with the glucagon, cyclic somatostatin (Centre de Recherche Sanofi, Montpellier, France: $3.8 \mu \mathrm{g} / \mathrm{min}$ ) was infused from 0 to $130 \mathrm{~min}$. All hormones were dissolved in $0.9 \% \mathrm{NaCl}$ containing $0.3 \mathrm{~g} / 100 \mathrm{ml}$ human serum albumin. For pulsatile glucagon delivery, a peristaltic pump (Hoechst, Frankfurt, FRG) was manually switched on or off, respectively, during 2 and $11 \mathrm{~min}$ of each cycle of $13 \mathrm{~min}$ during the $130 \mathrm{~min}$ of the experiment. As discussed elsewhere [11], such temporal pattern for glucagon infusion was chosen to attempt reproducing physiological glucagon pulsatility.

\section{Blood sampling}

Samples for determination of plasma glucagon were collected at $-20,0,13,16,26,29,39,42,52,55,65,68,78,81,91,93,104$, $107,117,120$ and $130 \mathrm{~min}$. To demonstrate the difference between continuous and pulsatile glucagon delivery, additional samples

for plasma glucagon measurement were collected at $0,3,7$ and 13 min of each of the three successive cycles occurring between 91 and $130 \mathrm{~min}$. After basal samples ( -20 and $0 \mathrm{~min}$ ) additional samples for plasma insulin, C-peptide and metabolite determinations were collected at $39,65,104$ and 130 min of each test while, for plasma glucose, samples were collected every $15 \mathrm{~min}$. Blood samples for hormone determinations were collected in $12 \mathrm{ml}$ tubes containing $1 \mathrm{ml}$ of an EDTA-Trasylol solution (Trasylol, Bayer, Leverkusen, FRG; $5000 \mathrm{U} / \mathrm{ml}$; disodium EDTA, $1.2 \mathrm{mg} / \mathrm{ml}$ ); blood for plasma glucose determination was collected in tubes containing a trace of sodium fluoride. All tubes were kept at $0-4{ }^{\circ} \mathrm{C}$ until processing.

\section{Analytical methods}

Except for plasma glucose which was determined immediately after the experiment with a Beckman AutoAnalyser (Fullerton, Calif., USA), (coefficient of variation of assay $3.0 \pm 0.9 \%$ ), all blood samples for hormone determination were centrifuged immediately after each experiment and the plasma sampleswerestored at $-20^{\circ} \mathrm{Cuntil}$ assay. Plasma glucagon (Byk-Gulden Mat Kit, Milan, Italy; with Unger $30 \mathrm{~K}$ antiserum; assay sensitivity $20 \mathrm{ng} /$; coefficient of variation $4.2 \pm 1.4 \%$ ), C-peptide (Byk Gulden Mat Kit; assay sensitivity $50 \mathrm{pmol} / \mathrm{l}$; coefficient of variation $4.0 \pm 1.6 \%$ ) and insulin (Bio-Data Kit; assay sensitivity $0.5 \mathrm{mU} / 1$; coefficient of variation $3.1 \pm 0.3 \%$ ) levels were all determined by radioimmunoassay as previously de- 

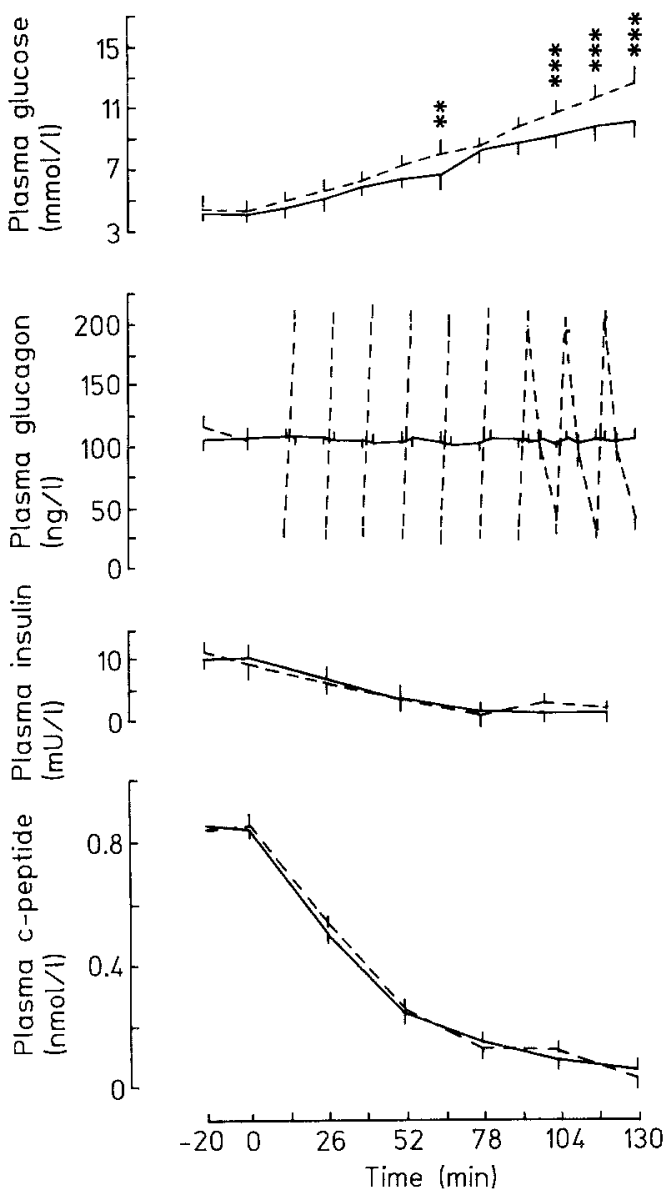

Fig.3. Plasma glucose, glucagon, insulin and C-peptide levels during continuous ( $\stackrel{-}{-}$ ) and pulsatile (----) glucagon infusion in aged subjects. Multiple collections of blood permitting demonstration of oscillations in plasma glucagon were performed from 91 to 130 min only. Results are expressed as mean $\pm \operatorname{SEM}(n=8)$. Statistically significant differences are: $* * \quad p<0.005 ; * * * p<0.001$

scribed $[5,11]$. Plasma glycerol, $\beta$-hydroxybutyrate and NEFA were determined according to Eggstein and Kuhlmann [13], Williamson and Mellanby [14] and Dole and Meinertz [15] respectively.

\section{Statistical analysis}

The areas under the curves of plasma glucagon levels were calculated using the trapezoidal method. Net increases in plasma glucose, glycerol, $\beta$-hydroxybutyrate and NEFA levels were calculated as differences between the highest value recorded at the end of the test and the mean basal value. After preliminary analysis of variance (ANOVA), all statistical comparisons between the two modes of glucagon infusion were performed by two-tailed $t$ tests for paired (pulsatile vs continuous glucagon infusion) and unpaired (young vs old subjects) data. $p$ values of 0.05 or less were considered statistically significant. All results were expressed as means \pm SEM.

\section{Results}

Pancreatic hormone and glucose data in young subjects (Fig. 1)

Continuous glucagon infusion resulted in steady plasma levels averaging $111 \pm 13 \mathrm{ng} / \mathrm{l}$ at the end of the experiment. Intermittent glucagon administration resulted in regular oscillations demonstrated during the $2 \mathrm{nd} h$ of the test by multiple blood sampling. Plasma glucagon levels for this mode of administration oscillated between $31 \pm 12$ and $202 \pm 22 \mathrm{ng} / \mathrm{l}$. No statistically significant differences were observed in plasma glucagon areas calculated between $\min 91$ and $\min 130(3.5 \pm 0.4 \mathrm{vs} 3.9 \pm 0.2 \mu \mathrm{g} \cdot \min / 1)$ during pulsatile and continuous glucagon delivery respectively. Basal plasma insulin ( $7 \pm 2$ vs $6 \pm 3 \mathrm{mU} / \mathrm{l})$ and Cpeptide $(0.92 \pm 0.04$ vs $0.88 \pm 0.06 \mathrm{nmol} / \mathrm{l})$ levels were similar and similarly inhibited by somatostatin at the end of the test in both modes of glucagon administration. Plasma glucose levels were similar in basal conditions. In response to glucagon replacement, plasma glucose showed a marked increase in both modes of hormone delivery. The hyperglycaemic effect of pulsatile glucagon delivery was significantly greater than that produced by continuous hormone administration (ANOVA: $\mathrm{F}=65.57 ; p<0.001$ ). In fact, in the last $65 \mathrm{~min}$ of the test, plasma glucose averaged $12.5 \pm 0.5$ and $10.3 \pm 0.3 \mathrm{mmol} / 1(p<0.01)$ during pulsatile and continuous glucagon delivery respectively.

\section{Lipolytic and ketogenic effects of glucagon in young subjects (Fig. 2)}

Basal plasma NEFA ( $566 \pm 46$ vs $551 \pm 42 \mu \mathrm{mol} / 1$ ), $\beta$-hydroxybutyrate $(202 \pm 13$ vs $206 \pm 14 \mu \mathrm{mol} / \mathrm{l})$ and glycerol ( $76 \pm 8$ vs $74 \pm 8 \mu \mathrm{mol} / 1)$ levels were similar in both experi-

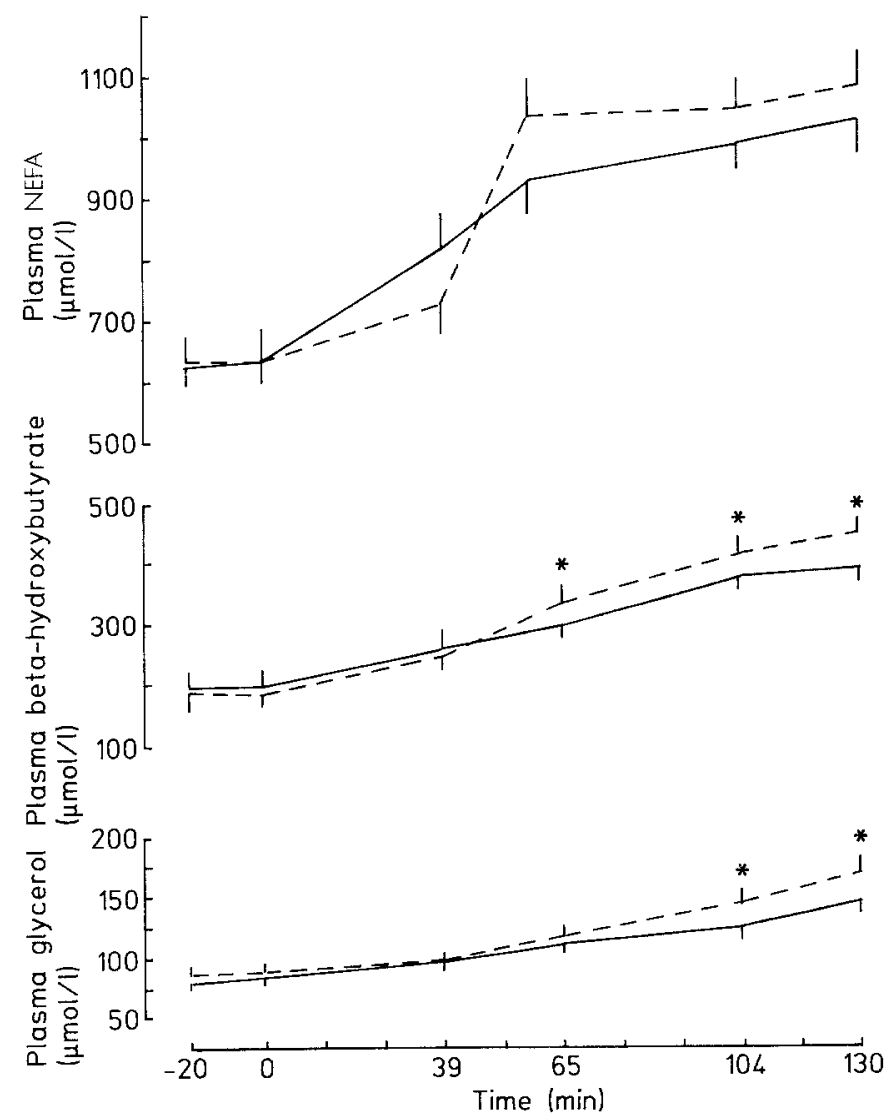

Fig.4. Plasma non-esterified fatty acid (NEFA), $\beta$-hydroxybutyrate and glycerol changes during continuous (- - ) and pulsatile (----) glucagon infusion in aged subjects. Results are expressed as mean \pm SEM $(n=8)$. Statistically significant differences is: $* p<0.05$ 

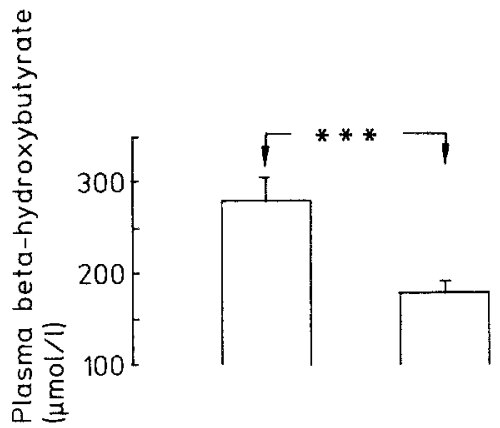

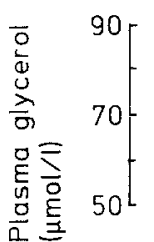

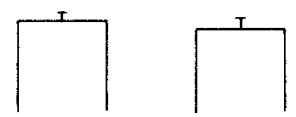

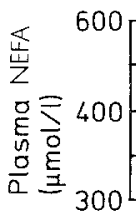
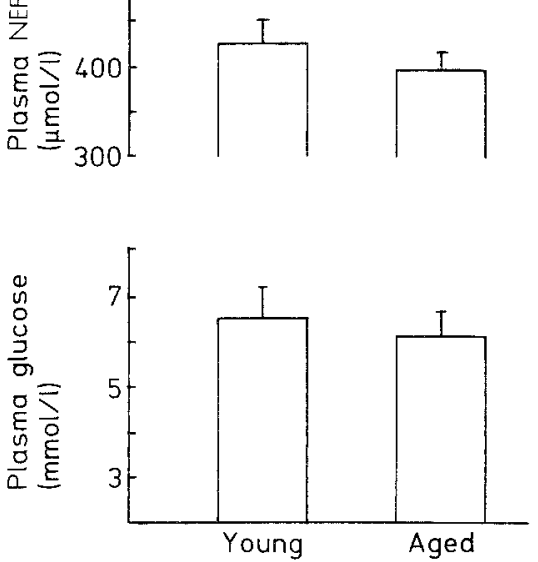

Fig. 5. Net increases in plasma $\beta$-hydroxybutyrate, glycerol, non-esterified fatty acid (NEFA) and glucose levels under the effect of continuous glucagon infusion in young and aged subjects $(n=8$ in each group). Statistically significant difference is: $* * * p<0.001$

ments. Glucagon replacement (and insulin deficiency) resulted in a remarkable increase in plasma NEFA, $\beta$-hydroxybutyrate and glycerol levels; the rise in these three parameters was significantly greater when glucagon was given in a pulsatile manner (ANOVA: $\mathrm{F}=15.32, p<0.001$; $\mathrm{F}=4.81, p<0.03 ; \mathrm{F}=16.57, p<0.001$ respectively).

\section{Pancreatic hormone and glucose data in aged subjects}

(Fig.3).

Continuous glucagon infusion resulted in steady plasma levels averaging $107 \pm 11 \mathrm{ng} / \mathrm{l}$ at the end of the experiment. Intermittent glucagon administration resulted in regular oscillations demonstrated during the 2 nd h of the test by multiple blood sampling. Plasma glucagon levels for this mode of administration oscillated between $38 \pm 10$ and $198 \pm 24 \mathrm{ng} / \mathrm{l}$. No statistically significant differences were observed in plasma glucagon areas calculated between $\min 91$ and $\min 130$ ( $3.3 \pm 0.6$ vs $3.9 \pm 0.3 \mu \mathrm{g} \cdot \mathrm{min} / \mathrm{l})$ during pulsatile and continuous glucagon delivery respectively.
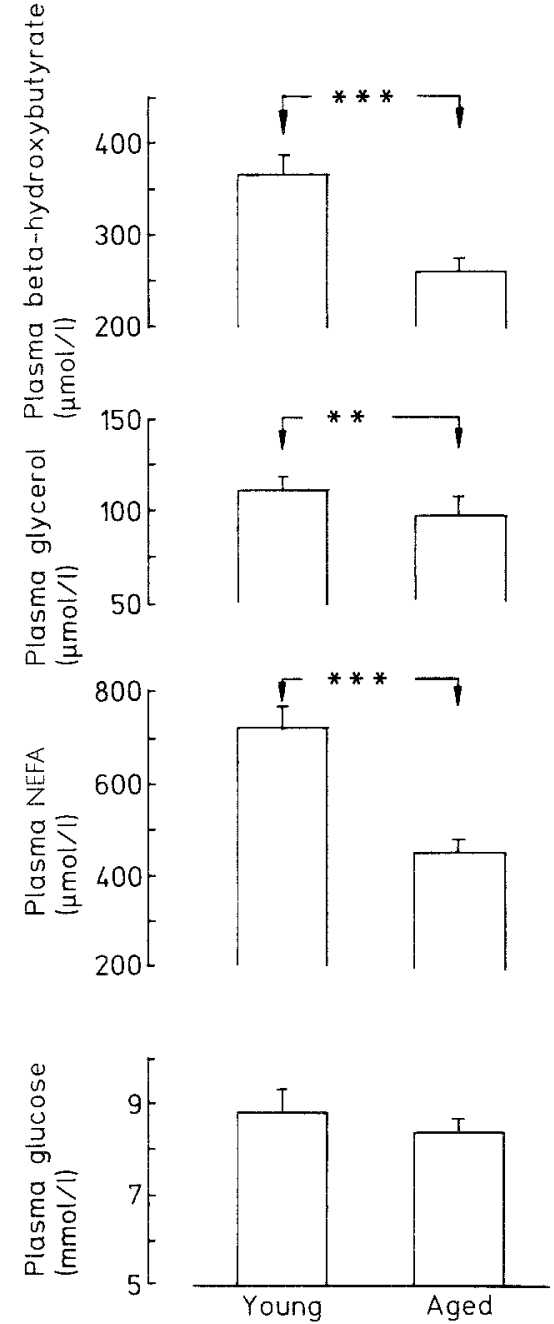

Fig.6. Net increases in plasma $\beta$-hydroxybutyrate, glycerol, nonesterified fatty acid (NEFA) and glucose levels under the effect of intermittent glucagon infusion in young and aged subjects $(n=8$ in each group). Statistically significant differences are: $* * x<0.02$; **** $p<0.001$

Basal plasma insulin ( $11 \pm 3$ vs $10 \pm 1 \mathrm{mU} / \mathrm{l})$ and $\mathrm{C}$ peptide $(0.83 \pm 0.03$ vs $0.86 \pm 0.05 \mathrm{nmol} / \mathrm{l})$ levels were similar and similarly affected by somatostatin infusion during both modes of glucagon administration. Plasma glucose levels were similar in basal conditions. As a result of insulin deficiency and glucagon infusion, plasma glucose evidenced a marked increase. Again, the rise in blood glucose was significantly greater when glucagon was perfused in a pulsatile manner (ANOVA: $F=27.16$; $p<0.001$ ). In the last $65 \mathrm{~min}$ of the test, plasma glucose averaged $10.6 \pm 0.6$ and $9.4 \pm 0.3 \mathrm{mmol} / \mathrm{l}(p<0.01)$ during pulsatile and continuous glucagon delivery respectively.

\section{Lipolytic and ketogenic effects of glucagon in aged subjects (Fig. 4)}

Basal plasma NEFA ( $641 \pm 42$ vs $633 \pm 39 \mu \mathrm{mol} / \mathrm{l}), \beta$-hydroxybutyrate $(193 \pm 13$ vs $199 \pm 14 \mu \mathrm{mol} / \mathrm{l})$ and glycerol $(80 \pm 8 \mathrm{vs} 78 \pm 8 \mu \mathrm{mol} / \mathrm{l})$ levels were similar in both experiments. As in the young subjects, insulin deficiency and glucagon replacement resulted in a significant rise in plas- 
ma NEFA, glycerol and $\beta$-hydroxybutyrate levels; here again, for glycerol (ANOVA: $\mathrm{F}=5.47, p<0.025$ ) and $\beta$ hydroxybutyrate (ANOVA: $\mathrm{F}=7.39, p<0.01$ ), the rise was slightly but significantly greater when glucagon was infused intermittently; for plasma NEFA levels, comparison by ANOVA of the two curves did not reveal statistical differences between continuous and pulsatile glucagon infusion $(\mathrm{F}=1.75 ; p=0.19)$.

\section{Effect of age (Figs. 5 and 6 )}

As shown in Figure 5, the net increases in plasma glucose, glycerol and NEFA were similar between the young and the aged subjects when glucagon was infused continuously; in contrast, the rise in plasma $\beta$-hydroxybutyrate in the aged was only about half that observed in the young subjects. Interestingly when glucagon was infused in a pulsatile manner (Fig. 6) the rises in plasma glycerol, NEFA and $\beta$-hydroxybutyrate levels were all significantly smaller in the aged subjects, while no significant differences were observed in the blood glucose responses. The differences in glucagon-induced $\beta$-hydroxybutyrate rises between young and elderly subjects were confirmed by ANOVA comparison of the plasma $\beta$-hydroxybutyrate curves from 0 to $130 \mathrm{~min}: \mathrm{F}=16.02, p<0.001$ when glucagon was infused continuously and $\mathrm{F}=16.79, p<0.001$ when the hormone was given in a pulsatile manner.

\section{Discussion}

As reviewed by our group and by others $[3,16]$, if no doubt exists on the pulsatile mode of glucagon and insulin secretion, the metabolic consequences of pulsatile glucagon delivery have been little investigated. Weigle et al. [8] have shown that in vitro the glucose produced by perifused rat hepatocytes exposed to pulsatile glucagon infusion exceeded by as much as twofold the response to the continuous infusion of the same amounts of glucagon. An analysis of the kinetics [9] of the hepatocyte response to transient glucagon stimuli showed that the temporal asymmetry of the response could account for the observed response curves. In addition, Komjati et al. [10] have demonstrated that the administration of glucagon to a perfused rat liver as a series of 3-min pulses induced a rise in integrated glucose production equivalent to that induced by the continuous infusion of twice as much glucagon. In vivo the only study on the respective effects of continuous and intermittent glucagon infusion has been reported by our group [11]; it led to negative results since pulsatile hyperglucagonaemia failed to significantly increase endogenous glucose production. As discussed elsewhere $[3,11]$, such negative results were probably due to the relatively high circulating levels of glucagon achieved, such high plasma levels being out of the "window" of glucagon concentrations for which the glucagon enhancement effect on liver glucose output has been observed in vitro $[8,9]$.

Thus, in the present study, we aimed at re-evaluating the metabolic effects of pulsatile glucagon delivery. Because animal studies had shown that glucagon effects are reduced by aging, we investigated two groups of volun- teers, one with young, the other with older subjects. Endogenous insulin and glucagon secretion were suppressed by a somatostatin infusion and glucagon only was replaced (either by a continuous or a pulsatile infusion). Whatever the mode of glucagon replacement or the age of the subjects, endogenous insulin secretion was similarly suppressed. Consequently the metabolic changes that we observed result from both progressive insulin deficiency and glucagon replacement. For the latter, the dose of glucagon chosen was such that, when infused continuously, plasma glucagon was maintained at its basal level. When the same dose of glucagon was delivered in a pulsatile manner, plasma glucagon oscillations were generated. Such oscillations exceed by far those spontaneously observed in the peripheral plasma [17] but not those reported in the portal vein $[18,19]$. Furthermore, the magnitude of the oscillations do not exceed plasma glucagon values observed in various physiological and pathophysiological conditions [20]. Whatever the age of the subjects investigated, in the face of declining insulin levels, pulsatile glucagon has significantly greater effects than continuous delivery on blood glucose, plasma NEFA, glycerol and $\beta$-hydroxybutyrate levels. According to in vitro data [8-10], it is likely that such superior efficacy of pulsatile vs continuous glucagon delivery on enhancing plasma glucose levels has to be ascribed to an increased action of the pulsatile hormone on hepatic glucose production.

As reviewed elsewhere [21], the stimulatory effect that glucagon exerts on lipolysis in man can only be detected in insulin deprivation, as is the case in the present study. In such a condition, the higher circulating levels of NEFA and glycerol during pulsatile glucagon delivery are likely to result from increased adipose tissue lipolysis; it should be kept in mind, however, that plasma levels of NEFA and glycerol are also affected by liver uptake of these metabolites for ketogenesis and gluconeogenesis respectively, processes which are likely to be stimulated in our experimental conditions. In both groups of subjects, pulsatile glucagon has greater effects on the rise in plasma $\beta$-hydroxybutyrate levels, an index of ketogenesis. As reviewed by McGarry and Foster [22], glucagon-induced ketogenesis is favoured by insulin deficiency (as it is induced in our study by somatostatin infusion) and by high plasma NEFA levels, as also observed here. Our study design does not allow for a decision on whether the greater effect of pulsatile glucagon on ketogenesis results from a greater effect on the liver itself or from an increased availability of NEFA through greater stimulation of adipose tissue lipolysis.

Finally, our study has shown a clear-cut reduction by age of the lipolytic and ketogenic (but not hyperglycaemic) actions of glucagon. A reduced effect of glucagon on rat adipose tissue lipolysis has been previously reported [23-25] but in these studies it was sometimes difficult to decide whether the resistance to glucagon was linked to the size of the adipocytes (which was greater in older animals) or to the age of the animals. In the present study, it should be stressed that the reduced lipolytic response to pulsatile glucagon seems to be age-dependent, since young and aged subjects had a similar BMI and none were obese. Studies by Cooper et al. [24] suggest that the reduced glucagon-induced lipolysis associated with aging 
results from a marked decline in the responsiveness of adipocyte adenylate cyclase to glucagon. The ketogenic response to glucagon is reduced in the aged subjects whatever the mode of glucagon delivery. Such a finding is in agreement with recent data by Okuda et al. [12] who have demonstrated in vivo and in vitro a marked decrease of the effect of glucagon on ketogenesis by aging in rats and have suggested that this hepatic unresponsiveness may be one of the major causes of hyperosmolar non-ketotic coma in elderly people. They have attributed the unresponsiveness to glucagon in old rat livers to a desensitization of the glucagon receptor adenylate cyclase system [12]. By contrast, the similar hyperglycaemic response to continuous or pulsatile glucagon delivery at different ages, a finding also found in rats by Okuda et al. [12] might be explained by the presence of another system such as the $\mathrm{Ca}^{++}$-calmodulin messenger which participates in the mechanism of the stimulatory effect of glucagon on hepatic glycogenolysis [26] and might be not affected by age.

In conclusion, in the presence of somatostatin-induced insulin deficiency, pulsatile glucagon exerts greater effects on blood glucose, plasma NEFA, glycerol and $\beta$-hydroxybutyrate levels than its continuous delivery. In the elderly, the lipolytic and ketogenic, but not the hyperglycaemic, responses to glucagon are significantly reduced: the extent to which such a finding is important for understanding the pathophysiology of hyperosmolar non-ketotic coma in elderly people [12] is purely hypothetical and requires further study.

Acknowledgements. This work was performed as part of a cooperative project between the Universities of Naples (Italy) and Liège (Belgium). We acknowledge the help of the Fonds National de la Recherche Scientifique (FNRS) and of the Fonds de Recherche de la Faculté de Médecine of the University of Liège. We thank Mrs E. Vaessen-Petit for her expert secretarial help.

\section{References}

1. Goodner CJ, Walike BC, Koerker DJ, Ensinck JW, Brown AC, Chideckel E, Palmer JC, Kalnasy L (1977) Insulin, glucagon and glucose exhibit synchronous sustained oscillations in fasting monkeys. Science 195: 177-179

2. Lang DA, Matthews DR, Peto J, Turner RC (1979) Cyclic oscillations of basal plasma glucose and insulin concentrations in human beings. N Engl J Med 301: 1023-1027

3. Lefèbvre PJ, Paolisso G, Scheen AJ, Henquin JC (1987) Pulsatility of insulin and glucagon release: physiological significance and pharmacological implications. Diabetologia 30: 443-452

4. Matthews DR, Naylor BA, Jones RG, Ward GM, Turner RC (1983) Pulsatile insulin has greater hypoglycemic effect than continuous delivery. Diabetes 32: 617-621

5. Paolisso G, Sgambato S, Passariello N, Scheen AJ, D'Onofrio F, Lefèbvre PJ (1987) Greater efficacy of pulsatile insulin in type I diabetics critically depends on plasma glucagon levels. Diabetes 36: $566-570$

6. Bratusch-Marrain PR, Komjati M, Waldhäusl WK (1986) Efficacy of pulsatile versus continuous insulin administration on hepatic glucose production and glucose utilization in type 1 diabetic humans. Diabetes 35: 922-926

7. Paolisso G, Scheen A, Lefèbvre PJ (1987) Greater inhibition of endogenous glucose production by pulsatile insulin delivery at basal glucagon levels in normal man. Diabetologia 30:566A

8. Weigle DS, Koerker DJ, Goodner CJ (1984) Pulsatile glucagon delivery enhances production by perifused rat hepatocytes. Am J Physiol 247: E564-E568
9. Weigle DS, Goodner CJ (1986) Evidence that the physiological pulse frequency of glucagon secretion optimizes glucose production by perifused rat hepatocytes. Endocrinology 118: 1606-1613

10. Komjati M, Bratusch-Marrain P, Waldhäusl W (1986) Superior efficacy of pulsatile versus continuous hormone exposure on hepatic glucose production in vitro. Endocrinology 118: 312-319

11. Paolisso G, Scheen AJ, Luyckx AS, Lefèbvre PJ (1987) Pulsatile hyperglucagonemia fails to increase hepatic glucose production in normal man. Am J Physiol 252: E1-E7

12. Okuda Y, Kawai K, Yamashita K (1987) Age-related change in ketone body metabolism: diminished glucagon effect on ketogenesis in adult rats. Endocrinology 120:2152-2157

13. Eggstein M, Kuhlmann E (1974) Triglycerides and glycerol; determination after alkaline hydrolysis. In: Bergmeyer HU (ed) Methods of enzymatic analysis, Vol 4. Verlag Chemie, Weinheim, and Academic Press Inc, New York, pp 1825-1831

14. Williamson DH, Mellanby J (1974) D-(-)-3 Hydroxybutyrate. In: Bergmeyer IUU (ed) Methods of enzymatic analysis, Vol 4. Verlag Chemie Weinheim and Academic Press Inc, New York, pp 1836-1839

15. Dole VP, Meinertz H (1960) Microdetermination of long chain fatty acids in plasma and tissues. J Biol Chem 235:2595-2599

16. Weigle DS (1987) Pulsatile secretion of fuel-regulatory hormones. Diabetes 36: 764-775

17. Unger RH, Lefèbvre PJ (1972) Glucagon physiology. In: Lefèbvre PJ, Unger RH (eds) Glucagon. Molecular physiology, clinical and therapeutic implications. Pergamon Press, Oxford, pp 213-244

18. Hansen BC, Jen K-LC, Koerker DJ, Goodner CJ, Wolfe RA (1982) Influence of nutritional state on periodicity in plasma insulin levels in monkeys. Am J Physiol 242: R255-R260

19. Jaspan JB, Lever E, Polonsky KS, Van Cauter E (1986) In vivo pulsatility of pancreatic islet peptides. Am J Physiol 251: E215E226

20. Lefèbvre PJ (ed) (1983) Glucagon (Handbook of experimental pharmacology, vol 66 I and II). Springer, Berlin Heidelberg New York

21. Lefèbvre PJ (1983) Glucagon and adipose tissue lipolysis. In: Lefèbvre PJ (ed) Glucagon I. Handbook of experimental pharmacology, Vol 66. Springer, Berlin Heidelberg New York, pp 419440

22. McGarry JD, Foster DW (1983) Glucagon and ketogenesis. In: Lefèbvre PJ (ed) Glucagon I. Handbook of experimental pharmacology, Vol 66. Springer, Berlin Heidelberg New York pp 383-398

23. Holmm G, Jacobsson B, Björntorp P, Smith U (1975) Effect of age and cell size on rat adipose tissue metabolism. J Lipid Res 16: $461-464$

24. Cooper B, Weinblatt F, Gregerman RI (1977) Enhanced activity of hormone-sensitive adenylate cyclase during dietary restriction in the rat: dependance on age and relation to cell size. J Clin Invest 59:467-474

25. Bertrand HA, Masoro EJ, Byung PYU (1980) Maintenance of glucagon-promoted lipolysis in adipocytes by food restriction. Endocrinology 107: 591-595

26. Corvera S, Huerta-Bahena J, Pelton JT, Hruby VJ, Trivedi D, Garcia-Sainz JA (1984) Metabolic effects and cyclic AMP produced by glucagon, (1-N-triitrophenylhistidine, 12-homoarginine) glucagon, and forskolin in isolated rat hepatocytes. Bioch Bioph Acta 804: 434

Received: 22 June 1989

and in revised form: 16 November 1989

Prof. P.Lefèbvre

Service Diabète-Nutrition

Maladies Métaboliques

C. H. U. Sart Tilman (B 35)

B-4000 Liege 1

Belgium 